\title{
Microdialysis for the Assessment of Intervertebral Disc and Vertebral Cancellous Bone Metabolism in a Large Porcine Model
}

\author{
MATS BUE ${ }^{1,2}$, PELLE HANBERG ${ }^{1,2}$, MAJA B. THOMASSEN $^{2}$, MIKKEL TØTTRUP ${ }^{3}$, \\ THEIS M. THILLEMANN ${ }^{2,4}$, KJELD SØBALLE ${ }^{2,4}$ and HANNE BIRKE-SØRENSEN ${ }^{2}$ \\ ${ }^{1}$ Department of Orthopaedic Surgery, Horsens Regional Hospital, Horsens, Denmark; \\ ${ }^{2}$ Orthopaedic Research Unit, Aarhus University Hospital, Aarhus, Denmark; \\ ${ }^{3}$ Department of Orthopaedic Surgery, Aalborg University Hospital, Fars $\phi$, Denmark; \\ ${ }^{4}$ Department of Orthopaedic Surgery, Aarhus University Hospital, Aarhus, Denmark
}

\begin{abstract}
Background/Aim: It remains challenging to evaluate the in vivo pathophysiological biochemical characteristics in spine tissue, due to lack of an applicable model and feasible methods. The aim of this study was to apply microdialysis for the assessment of basic metabolites from the C3-C4 intervertebral disc, C3 vertebral cancellous bone and subcutaneous adipose tissue in a large porcine model. Materials and Methods: In 7 pigs, glucose, pyruvate, lactate and glycerol concentrations were evaluated in an 8 hour sampling period. Results: The mean lactate/pyruvate $(L / P)$ ratios for the intervertebral disc and vertebral cancellous bone were comparable and exceeded the ischemic cut-off value of 25 for the entire sampling interval. For subcutaneous adipose tissue, the L/P ratio was below the ischemic cut-off. Conclusion: This exploratory study confirms previous findings of ischemia in bone and the intervertebral disc. This encourages new microdialysis study designs in spine tissue employing large porcine models to create new knowledge and a greater understanding of the metabolism and pathogenesis in spine tissue.
\end{abstract}

Degenerative back disorders are integral parts of many human lives, and have serious effects on the individuals, public health and economy $(1,2)$. However, for most of these disorders, the pathogenesis is not fully understood $(1,2)$. At present, the morphology of vertebral cancellous bone and the intervertebral

This article is freely accessible online.

Correspondence to: Mats Bue, Department of Orthopaedic Surgery, Horsens Regional Hospital, Sundvej 30, Horsens, Denmark. Tel: +45 25599294, e-mail: matsbue6@rm.dk

Key Words: Microdialysis, spine, metabolism, ischemia, intervertebral disc, vertebral cancellous bone. disc is well described while the physiological and pathophysiological biochemistry in these compartments are not fully understood $(3,4)$. One of the reasons for this, is the lack of an applicable model and feasible methods to assess the degenerative processes through biochemical reactions. Traditionally, biochemical and physiological characteristics of vertebral cancellous bone and the intervertebral disc have almost only been evaluated using tissue samples and discectomy (5-8). As opposed to these methods, microdialysis has emerged as a promising tool with the potential to overcome some of the inherent limitations associated with the existing methods. Microdialysis as a method is, among others, advantaged by dynamic and simultaneous in vivo sampling from multiple compartments of the unbound water-soluble molecules from the interstitial space of the investigated tissue $(9,10)$. For the particular cases of bone tissue and the intervertebral disc, microdialysis has only been applied for the assessment of metabolism in the femoral head of humans and pigs, and in a cadaver study, respectively (11-14). To date, microdialysis sampling from vertebral cancellous bone and the intervertebral disc has been limited to antimicrobials in a porcine model $(15,16)$. As it may be challenging to identify a clinical model to assess in vivo spine tissue biochemistry without causing any harm to the patients, a large porcine model may prove to be important for further understanding of the metabolism and pathogenesis in spine tissue. The present study aimed to apply microdialysis for the assessment of basic metabolic markers from the $\mathrm{C} 3-\mathrm{C} 4$ intervertebral disc, the $\mathrm{C} 3$ vertebral cancellous bone and subcutaneous adipose tissue in a large porcine model.

\section{Materials and Methods}

The study was approved by the Danish Animal Experiments Inspectorate (license No. 2017/15-0201-01184). All animals were cared for in accordance with the principles laid down by the 
European Union Directive 2010/63/EU for Protection of Animals used for Scientific Purposes. This study was based on microdialysis dialysates obtained from 7 experimental pigs (Danish Landrace Breed; weight $78-82 \mathrm{~kg}$ ). The pigs were included in a pharmacokinetic study investigating the penetration of vancomycin into the $\mathrm{C} 3-\mathrm{C} 4$ intervertebral disc, the $\mathrm{C} 3$ vertebral cancellous bone, and subcutaneous adipose tissue (15).

Study procedures. With the pig in supine position, and under fluoroscopic guidance, a drill hole with a diameter of $2 \mathrm{~mm}$ and a depth of $25 \mathrm{~mm}$ was created in the middle of the $\mathrm{C} 3$ vertebral body. In the caudal part of the $\mathrm{C} 2$ vertebral body, and parallel to the drill hole in $\mathrm{C} 3$, a Kirschner wire connected to a fixating device $\left(\right.$ PEBAX $^{\circledR},{ }^{\circledR}$ Dialysis AB, Stockholm, Sweden) was inserted. With the tip of a microdialysis catheter protruding approximately $30 \mathrm{~mm}$ from the tip of a splittable introducer, the catheter (membrane length $20 \mathrm{~mm}$ ) was attached to the fixating device using endoclips and placed in the drill hole in the $\mathrm{C} 3$ vertebral body. This manoeuvre was done to avoid displacement of the catheter. A splittable introducer with a needle was then inserted in the intervertebral disc between $\mathrm{C} 3$ and $\mathrm{C} 4$ parallel to, and in the middle of, the adjacent endplates. The needle was retracted, and a microdialysis catheter (membrane length $10 \mathrm{~mm}$ ) was placed in the splittable introducer. The splittable introducer was then retracted until the catheter membrane was fully exposed in the intervertebral disc. The catheter was fixed to the splittable introducer with endo clips. Fluoroscopy was applied for the evaluation of correct placement of the catheters in the $\mathrm{C} 3$ vertebral body and the $\mathrm{C} 3-\mathrm{C} 4$ intervertebral disc (15). As references, a subcutaneous adipose tissue catheter (membrane length $20 \mathrm{~mm}$ ) was inserted in the lateral part of the right thigh, and a central venous catheter was placed for subsequent venous blood sampling. After placement of all microdialysis catheters, a 30-min tissue equilibration period followed. The pigs were systemically given $1,000 \mathrm{mg}$ of vancomycin, and dialysates were collected with 40-min intervals for the first two hours and, thereafter, with 60-min intervals for the following six hours, resulting in a total of nine samples over eight hours. The dialysates were instantly placed in a $-80^{\circ} \mathrm{C}$ freezer until analysis. The penetration of vancomycin was found to be significantly incomplete and delayed to the intervertebral disc and vertebral cancellous bone. A more thorough discussion of the resulting pharmacokinetic data can be found elsewhere (15).

The pigs were kept under general anaesthesia during the entire surgery and sampling period, using a combination of fentanyl (0.35$0.5 \mathrm{mg} / \mathrm{h}$, continuous infusion) and propofol $(500-600 \mathrm{mg} / \mathrm{h}$, continuous infusion). Core temperature and arterial $\mathrm{pH}$ was monitored throughout the study and kept in the range of $36.2-39.1^{\circ} \mathrm{C}$ and 7.36-7.47, respectively. $0.9 \% \mathrm{NaCl}$ was given continuously (150 $\mathrm{ml} / \mathrm{h}$ ) to maintain normohydration and glucose was substituted when needed. Following collection of the last dialysates, the pigs were euthanised by an overdose of pentobarbital.

Microdialysis. In brief, microdialysis is a catheter-based method that allows for serial sampling of water-soluble molecules from the extracellular fluid in the tissue of interest by means of a semipermeable membrane at the tip of the microdialysis catheter $(9$, 10, 17). Molecules from the interstitial space will, hence, diffuse across the semipermeable membrane. The solution that passes through the catheter can be sampled in small vials for subsequent analysis. In this study the microdialysis setup consisted of CMA 107 precision pumps (M Dialysis AB, Stockholm, Sweden) and CMA 70 catheters (membrane length $20 \mathrm{~mm}$ and $10 \mathrm{~mm}$, molecular cutoff $20 \mathrm{kDa}$ ). All catheters were perfused with $0.9 \% \mathrm{NaCl}$ at a perfusion rate of $1 \mu \mathrm{l} / \mathrm{min}$ throughout the sampling time. Due to the continuous perfusion of the microdialysis system, there will never be obtained complete concentration equilibrium across the semipermeable membrane. Thus, the concentration in the dialysate represents a fraction of the true tissue concentration, expressed as relative recovery, and must be determined if absolute tissue concentrations are to be investigated. Relative recovery is affected by several factors such as perfusion rate, membrane type and length, tissue structure, and molecular weight. A detailed description of microdialysis can be found elsewhere $(9,10)$.

Metabolite markers. In the present study, dialysates from 7 pigs were used to estimate local concentrations of the following molecules; glucose, lactate, pyruvate and glycerol. Analysis of each molecule concentration was performed using a CMA600 microdialysis analyser (M Dialysis AB, Stockholm, Sweden). Conventionally, these four molecules and calculated ratios have been used for metabolic monitoring of living tissues (18).

Ischemia occurs when the supply of oxygen and substrates to tissues are reduced. Thus, ischaemic cells will be depleted of energy and the capacity to regenerate metabolites will decrease. The cell changes its metabolism from oxidative phosphorylation to anaerobic glycolysis to generate energy and preserve homeostasis. Accordingly, a reduction of oxygen supply will decrease the production of pyruvate with a following increase in lactate, resulting in an increase in the lactate/pyruvate $(\mathrm{L} / \mathrm{P})$ ratio $(14,19)$. A $\mathrm{L} / \mathrm{P}$ ratio above 25 is considered to signify ischemia (20). This ratio is a quantitative measure and independent of relative recovery $(21,22)$. Increased glycerol levels are correlated to cell membrane break down (21).

Statistics. The area under the concentration-time profiles $\left(\mathrm{AUC}_{0 \text {-last }}\right)$ for the metabolite markers were determined separately for each compartment for each pig by non-compartmental analysis using the pharmacokinetic-series of commands in Stata (v. 14.1, StataCorp LLC, College Station, TX, USA). The AUC-values were used to conduct pairwise comparisons between the compartments for each marker using the t-test. Specifically, the $\mathrm{AUC}_{0 \text {-last }}$ was calculated using the trapezoidal rule and a mixed model for repeated measurements taking the variance between pigs into account was applied. To evaluate if the metabolite markers decreased during the sampling period, a comparison of the concentration differences between the first $(20 \mathrm{~min})$ and last sample $(450 \mathrm{~min})$ was performed using the $t$-test. A $p$-value $<0.05$ was considered to be significant. All statistical analyses were performed using Stata.

\section{Results}

Except for one malfunctioning intervertebral disc catheter, data were obtained from all catheters. Mean concentrationtime profiles for all four metabolite markers are shown in Figure 1. Corresponding L/P ratios are depicted in Figure 2.

For glucose, pyruvate and lactate, the concentrations were found to be relatively constant throughout the 8-hour sampling period, except for the lactate and pyruvate concentrations in vertebral cancellous bone, in which both 


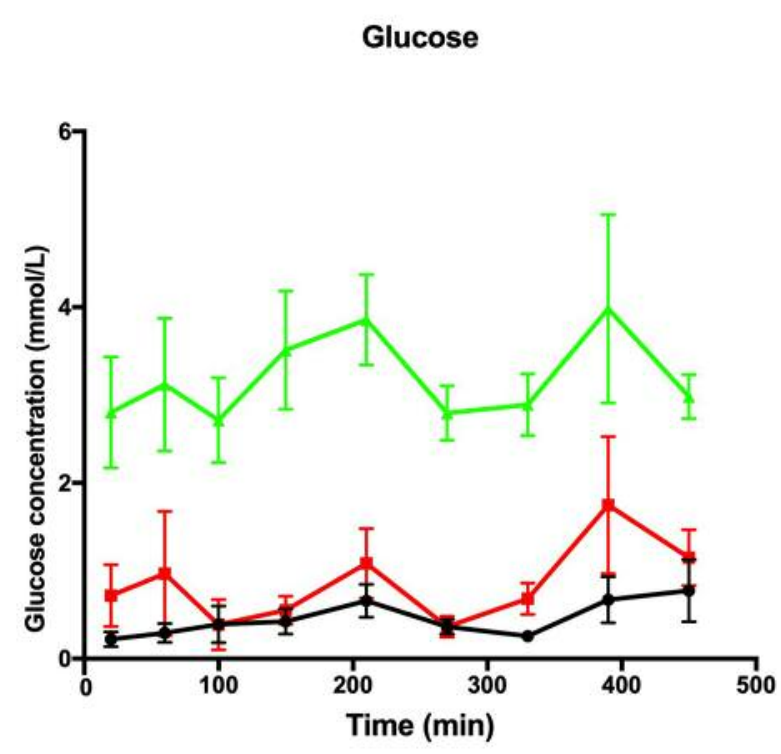

Glycerol

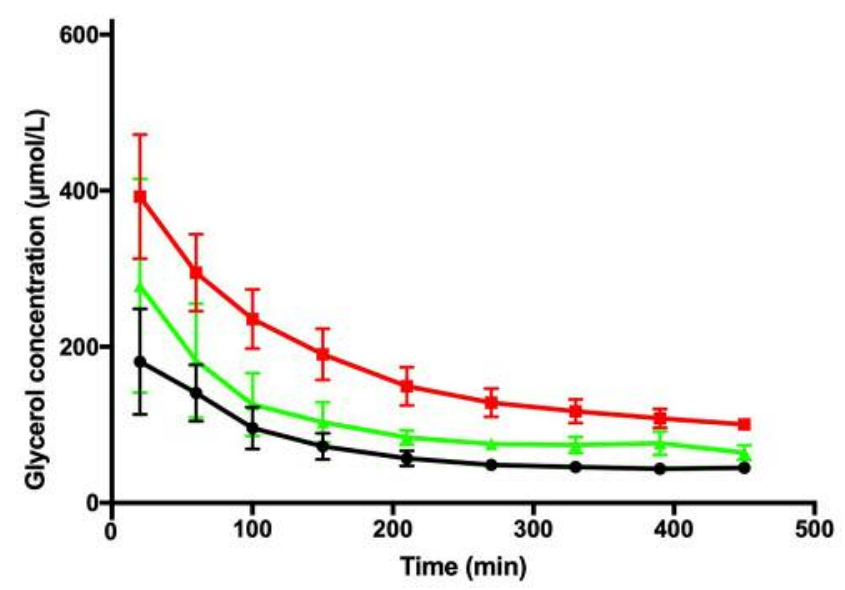

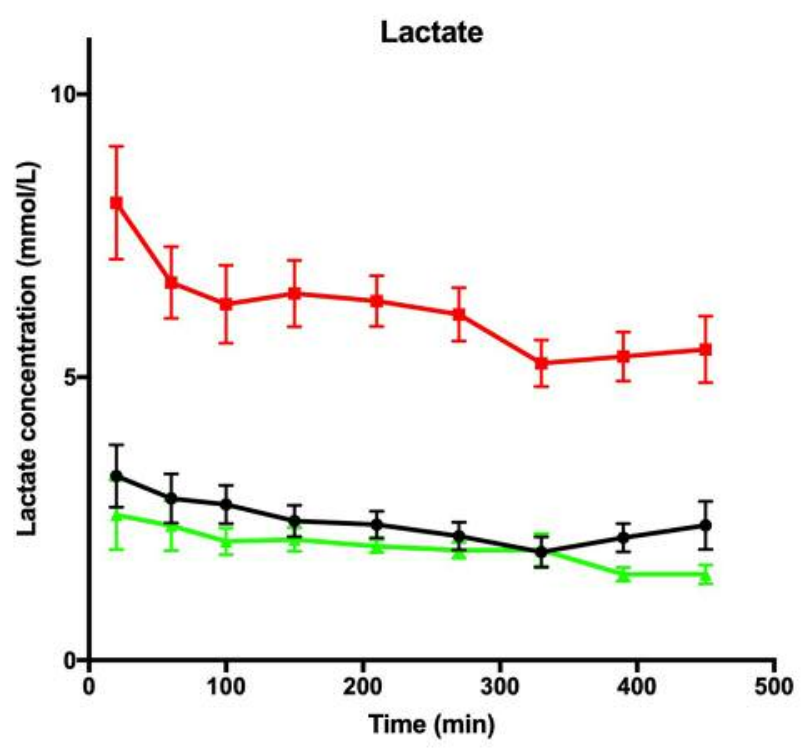

Pyruvate

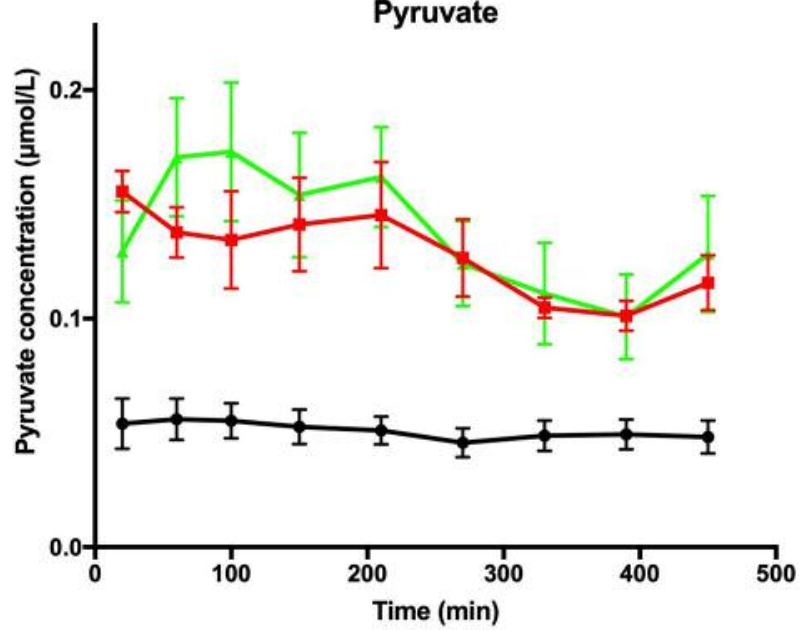

- Intervertebral disc

- Vertebral cancellous bone

- Subcutaneous adipose tissue

Figure 1. Mean concentration-time profiles for glucose, lactate, glycerol, and pyruvate. Bars represent standard error of the mean (SEM).

decreased during the sampling period $(p<0.04)$. The pyruvate concentrations were lower in the intervertebral disc in comparison to both vertebral cancellous bone and subcutaneous adipose tissue $(p<0.002)$. For lactate, the highest concentrations were found in vertebral cancellous bone $(p<0.001)$. The $\mathrm{L} / \mathrm{P}$ ratio was comparable in the intervertebral disc and vertebral cancellous bone, and in both positions approximately the double of the ischemic cut-off value of 25 , for the entire sampling interval. However, the elevated L/P ratios were obtained by different lactate and pyruvate profiles in the two compartments. For subcutaneous adipose tissue, the $\mathrm{L} / \mathrm{P}$ ratio was below the ischemic cut-off. The glucose concentrations were found to be highest in subcutaneous adipose tissue $(p<0.001)$, whereas they were lower and comparable in vertebral cancellous bone and the intervertebral disc. For glycerol, the vertebral cancellous bone concentrations were higher than in the intervertebral disc and subcutaneous adipose tissue $(p<0.005)$. Moreover, in all compartments, the glycerol concentration-time profiles displayed decreasing tendencies during this sampling period, although only in vertebral cancellous bone, this reached significance $(p<0.008)$. 


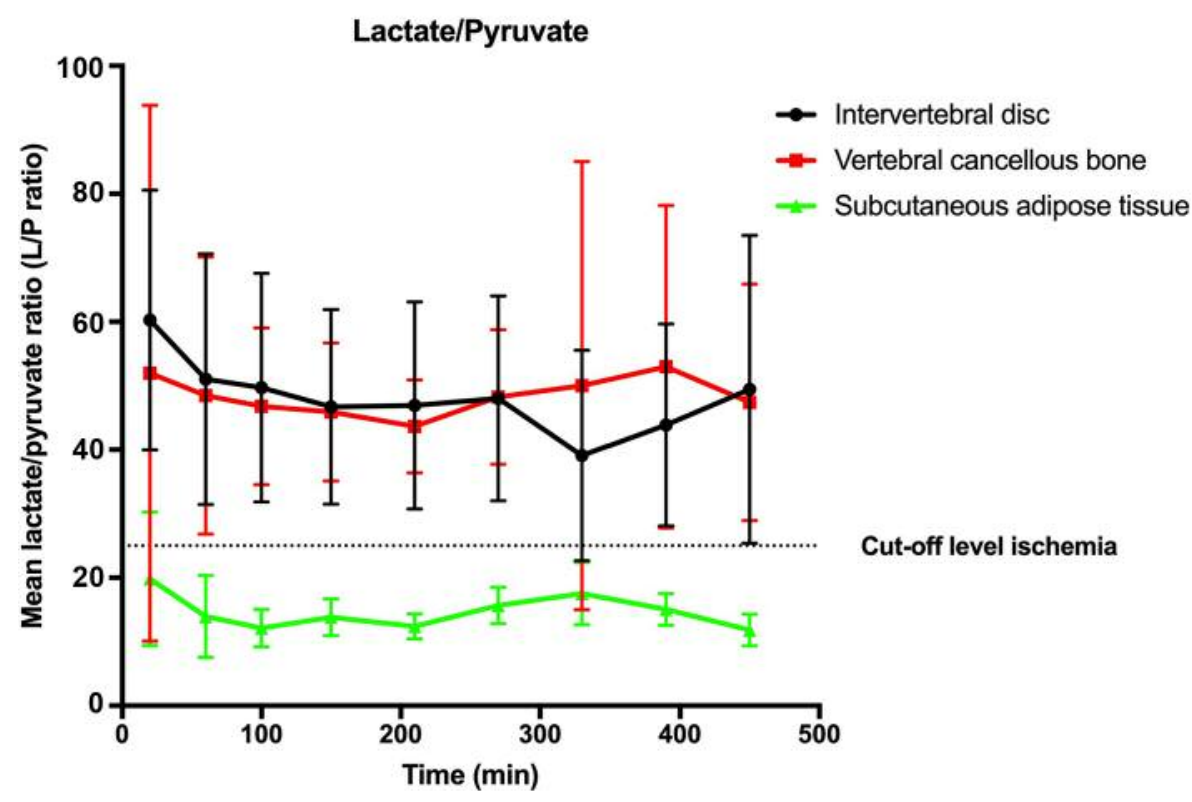

Figure 2. Mean lactate/pyruvate $(L / P)$ ratios for the intervertebral disc, vertebral cancellous bone and subcutaneous adipose tissue. Bars represent standard error of the mean (SEM). A cut-off level of 25 is inserted: values above the cut-off signify ischemia.

\section{Discussion}

To our knowledge, this is the first study to apply microdialysis for the assessment of in vivo basic metabolite markers from the intervertebral disc and vertebral cancellous bone. A markedly elevated mean $\mathrm{L} / \mathrm{P}$ ratio was demonstrated in the intervertebral disc and vertebral cancellous bone, with values of approximately 50 , which is considered to signify ischemia, for the entire sampling interval (20). Both the lactate and the pyruvate concentrations were higher in vertebral cancellous bone in comparison to the intervertebral disc, however, the $\mathrm{L} / \mathrm{P}$ ratios were comparable. In contrast, the mean $\mathrm{L} / \mathrm{P}$ ratio in subcutaneous adipose tissue was low, and the highest glucose concentrations were found in this compartment, which may indicate a higher glut of nutrients in the subcutaneous adipose tissue. The mean glycerol concentrations were highest in vertebral cancellous bone and displayed decreasing tendencies in all compartments throughout the sampling interval. Glycerol is liberated as a result of cell membrane damage. As previously demonstrated, the trauma of drilling in bone tissue results in initially elevated glycerol concentrations (12-14). The lowest mean glycerol concentrations were found in the intervertebral disc, which may be explained by a lower number of cells in this compartment.

To date, there is limited number of studies, feasible methods and applicable models to describe the in vivo physiological and pathophysiological biochemical characteristics in vertebral cancellous bone and the intervertebral disc. The present study demonstrates that microdialysis may be a suitable tool to dynamically evaluate the biochemical properties in spine tissue with the potential to generate a larger understanding of the metabolism and pathogenesis of degenerative back disorders. As seen in other experimental setups $(23,24)$, large porcine models may prove to be significantly important, since it may be problematic to identify certain applicable clinical setups. For future studies, and in terms of clinical relevance, study designs evaluating the effect of puncture of the intervertebral disc, infection, surgical intervention, instrumentation, etc. on the local metabolism in spine tissue seem attractive.

The pathogenesis of degenerative back disorders is not fully understood $(1,2)$. In vertebral cancellous bone and the intervertebral disc, there are multiple causes that can lead to tissue degeneration, including infection, inflammation, ageing, tumours, fractures, diabetes, etc. (25). One of the reasons for the degenerative processes may be a reduced tissue perfusion with resulting ischemia. However, certain tissues, e.g. articular chondrocytes and cells within the intervertebral disc, have adopted to and confide in avascular conditions as they merely rely on diffusion of nutrients and oxygen from the nearest blood vessel (26-29). In that sense, the findings from the intervertebral disc in the present study are more endorsing than surprising. For vertebral cancellous bone, ischemic conditions have not previously been shown. However, these findings are consistent with previous microdialysis results of ischemia in bone demonstrated in the femoral head of both humans and pigs (12-14). Altogether, the findings from the present study confirms previous findings of ischemia in bone and the intervertebral disc. 
This study was confined to only sample and quantified four basic metabolite markers. In principal, microdialysis allows for sampling of all water-soluble molecules below the cut-off value of the specific semipermeable membrane, such as $e . g$. inflammatory markers, perfusion-related molecules and cytokines. This may be of interest and have the potential to bring new knowledge in the understanding of the physiology and pathophysiology in vertebral cancellous bone and the intervertebral disc. Nonetheless, it appears that microdialysis remains a sampling technique, that needs to be linked to an appropriate analytical assay.

With reference to reduction, refinement and replacement (the 3Rs), the present study was based on microdialysis dialysates previously obtained and included in a pharmacokinetic study investigating the penetration of vancomycin into the $\mathrm{C} 3-\mathrm{C} 4$ intervertebral disc, the $\mathrm{C} 3$ vertebral cancellous bone, and subcutaneous adipose tissue (15). As such, the present study fulfils the expectation of reduction, as the material is collected from previously used pigs, instead of using new pigs to generate similar results. On the other hand, this produces a number of appreciable limitations. Since sampling had to be started after surgery, it was not possible to determine baseline values in the compartments. Moreover, the results can only be used for the changes in the concentrations ratios and the variation between compartments since the relative recovery for the four metabolite markers were not determined. For future in vivo microdialysis pathophysiological studies in the intervertebral disc and vertebral cancellous bone, the application of a lower perfusion flow rate, equal membrane lengths, determination of relative recovery, and a different sampling interval may be considered. Finally, the study was conducted on juvenile pigs (aged 5 months), which had to be kept under general anaesthesia during the entire sampling interval. Induction of general anaesthesia is known to cause physiological alterations that may have affected the local tissue metabolism. Although pigs have been shown to resemble humans in terms of physiology, anatomy and bone inflammation and regeneration (30-33), the porcine intervertebral disc and vertebral cancellous bone differ from that of humans in several ways (15).

In conclusion, microdialysis was successfully applied to describe basic metabolism in the intervertebral disc and vertebral cancellous bone in a large porcine model. This exploratory study confirms previous findings of ischemia in bone and the intervertebral disc. This encourages new microdialysis study designs in spine tissue employing large porcine models to create new knowledge and a greater understanding of the metabolism and pathogenesis in spine tissue.

\section{Conflicts of Interest}

The Authors declare no potential conflicts of interest with respect to the research, authorship and/or publication of this article.

\section{Authors' Contributions}

MB, PH, MBT, MT, TMT, KS and HBS initiated and designed the study. MB, MBT, and PH conducted the surgery and MB placed all the probes. MB, MBT, and PH collected the data and analysed the metabolite markers. Statistical analysis and interpretation of data was done by MB, PH, MBT, MT, TMT, KS and HBS. All Authors drafted and revised the manuscript.

\section{Acknowledgements}

This work was supported by unrestricted grants from the Augustinus Foundation, the Lippmann Foundation, the Knud and Edith Eriksens Memorial Foundation, the Søster and Verner Lipperts Foundation, and the Health Research Fund of Central Denmark Region.

\section{References}

1 Manek NJ and MacGregor AJ: Epidemiology of back disorders: Prevalence, risk factors, and prognosis. Curr Opin Rheumatol 17(2): 134-140, 2005. PMID: 15711224. DOI: 10.1097/01.bor.00 00154215.08986 .06

2 Katz JN: Lumbar disc disorders and low-back pain: Socioeconomic factors and consequences. J Bone Joint Surg Am 88(Suppl 2): 2124, 2006. PMID: 16595438. DOI: 10.2106/JBJS.E.01273

3 Cassinelli EH, Hall RA and Kang JD: Biochemistry of intervertebral disc degeneration and the potential for gene therapy applications. Spine J 1(3): 205-214, 2001. PMID: 14588349. DOI: 10.1016/s1529-9430(01)00021-3

4 Roberts S, Evans H, Trivedi J and Menage J: Histology and pathology of the human intervertebral disc. J Bone Joint Surg Am 88(Suppl 2): 10-14, 2006. PMID: 16595436. DOI: 10.2106/JBJS.F.00019

5 Rannou F, Lee TS, Zhou RH, Chin J, Lotz JC, MayouxBenhamou MA, Barbet JP, Chevrot A and Shyy JY: Intervertebral disc degeneration: The role of the mitochondrial pathway in annulus fibrosus cell apoptosis induced by overload. Am J Pathol 164(3): 915-924, 2004. PMID: 14982845. DOI: 10.1016/S0002-9440(10)63179-3

6 Court C, Colliou OK, Chin JR, Liebenberg E, Bradford DS and Lotz JC: The effect of static in vivo bending on the murine intervertebral disc. Spine J 1(4): 239-245, 2001. PMID: 14588327. DOI: 10.1016/s1529-9430(01)00056-0

7 O’Neill CW, Liu JJ, Leibenberg E, Hu SS, Deviren V, Tay BK, Chin CT and Lotz JC: Percutaneous plasma decompression alters cytokine expression in injured porcine intervertebral discs. Spine J 4(1): 88-98, 2004. PMID: 14749197. DOI: 10.1016/ s1529-9430(03)00423-6

8 Parkinson IH, Badiei A, Stauber M, Codrington J, Muller R and Fazzalari NL: Vertebral body bone strength: The contribution of individual trabecular element morphology. Osteoporos Int 23(7): 1957-1965, 2012. PMID: 22086309. DOI: 10.1007/s00198-011$1832-6$

9 Joukhadar C and Muller M: Microdialysis: Current applications in clinical pharmacokinetic studies and its potential role in the future. Clin Pharmacokinet 44(9): 895-913, 2005. PMID: 16122279. DOI: 10.2165/00003088-200544090-00002

10 Muller M: Science, medicine, and the future: Microdialysis. BMJ 324(7337): 588-591, 2002. PMID: 11884326. DOI: $10.1136 / \mathrm{bmj} .324 .7337 .588$ 
11 Liljensten E, Skog G, Sonnergren H and Jensen-Waern M: Microdialysis as a method for biochemical and physiological studies of the porcine and human disc. Lab Anim 44(2): 118123, 2010. PMID: 20357316. DOI: 10.1258/la.2010.009107

12 Bogehoj M, Emmeluth $\mathrm{C}$ and Overgaard S: Blood flow and microdialysis in the human femoral head. Acta Orthop 78(1): 5662, 2007. PMID: 17453393. DOI: $10.1080 / 17453670610013420$

13 Bogehoj MF, Emmeluth C and Overgaard S: Microdialysis in the femoral head of the minipig and in a blood cloth of human blood. Acta Orthop 82(2): 241-245, 2011. PMID: 21428845. DOI: $10.3109 / 17453674.2011 .566132$

14 Lorenzen ND, Stilling M, Ulrich-Vinther M, Trolle-Andersen N, Pryno T, Soballe $\mathrm{K}$ and Birke-Sorensen $\mathrm{H}$ : Increased postoperative ischemia in the femoral head found by microdialysis by the posterior surgical approach: A randomized clinical trial comparing surgical approaches in hip resurfacing arthroplasty. Arch Orthop Trauma Surg 133(12): 1735-1745, 2013. PMID: 24100766. DOI: 10.1007/s00402-013-1851-1

15 Bue M, Hanberg P, Tottrup M, Thomassen MB, Birke-Sorensen H, Thillemann TM, Andersson TL and Soballe K: Vancomycin concentrations in the cervical spine after intravenous administration: Results from an experimental pig study. Acta Orthop 89(6): 683-688, 2018. PMID: 30080983. DOI: $10.1080 / 17453674.2018 .1501548$

16 Hanberg P, Bue M, Birke Sorensen H, Soballe K and Tottrup M: Pharmacokinetics of single-dose cefuroxime in porcine intervertebral disc and vertebral cancellous bone determined by microdialysis. Spine J 16(3): 432-438, 2016. PMID: 26620946. DOI: 10.1016/j.spinee.2015.11.031

17 Tottrup M, Soballe K, Bibby BM, Hardlei TF, Hansen P, Fuursted K, Birke-Sorensen H and Bue M: Bone, subcutaneous tissue and plasma pharmacokinetics of cefuroxime in total knee replacement patients - a randomized controlled trial comparing continuous and short-term infusion. APMIS 127(12): 779-788, 2019. PMID: 31515843. DOI: 10.1111/apm.12996

18 Ungerstedt U: Microdialysis - principles and applications for studies in animals and man. J Intern Med 230(4): 365-373, 1991. PMID: 1919432. DOI: 10.1111/j.1365-2796.1991.tb00459.x

19 Ejaz A, Laursen AC, Kappel A, Jakobsen T, Nielsen PT and Rasmussen S: Tourniquet induced ischemia and changes in metabolism during tka: A randomized study using microdialysis. BMC Musculoskelet Disord 16: 326, 2015. PMID: 26510621. DOI: 10.1186/s12891-015-0784-y

20 Ungerstedt $\mathrm{U}$ and Rostami E: Microdialysis in neurointensive care. Curr Pharm Des 10(18): 2145-2152, 2004. PMID: 15281890. DOI: $10.2174 / 1381612043384105$

21 Hutchinson PJ, Jalloh I, Helmy A, Carpenter KL, Rostami E, Bellander BM, Boutelle MG, Chen JW, Claassen J, DahyotFizelier C, Enblad P, Gallagher CN, Helbok R, Hillered L, Le Roux PD, Magnoni S, Mangat HS, Menon DK, Nordstrom CH, O'Phelan KH, Oddo M, Perez Barcena J, Robertson C, RonneEngstrom E, Sahuquillo J, Smith M, Stocchetti N, Belli A, Carpenter TA, Coles JP, Czosnyka M, Dizdar N, Goodman JC, Gupta AK, Nielsen TH, Marklund N, Montcriol A, O'Connell MT, Poca MA, Sarrafzadeh A, Shannon RJ, Skjoth-Rasmussen J, Smielewski P, Stover JF, Timofeev I, Vespa P, Zavala E and Ungerstedt U: Consensus statement from the 2014 international microdialysis forum. Intensive Care Med 41(9): 1517-1528, 2015. PMID: 26194024. DOI: 10.1007/s00134-015-3930-y
22 Engstrom M, Polito A, Reinstrup P, Romner B, Ryding E, Ungerstedt $\mathrm{U}$ and Nordstrom $\mathrm{CH}$ : Intracerebral microdialysis in severe brain trauma: The importance of catheter location. J Neurosurg 102(3): 460-469, 2005. PMID: 15796380. DOI: 10.3171/jns.2005.102.3.0460

23 Palek R, Jonasova A, Rosendorf J, Mik P, Bajcurova K, Hosek P, Moulisova V, Eberlova L, Haidingerova L, Brzon O, Bednar L, Kriz T, Dolansky M, Treska V, Tonar Z, Vimmr J and Liska $\mathrm{V}$ : Allogeneic venous grafts of different origin used for portal vein reconstruction after pancreaticoduodenectomy experimental study. Anticancer Res 39(12): 6603-6620, 2019. PMID: 31810926. DOI: 10.21873/anticanres.13876

24 Mahringer A, Karamustafa S, Klotz D, Kahl S, Konkimalla VB, Wang Y, Wang J, Liu HY, Boechzelt H, Hao X, Bauer R, Fricker $\mathrm{G}$ and Efferth T: Inhibition of p-glycoprotein at the blood-brain barrier by phytochemicals derived from traditional chinese medicine. Cancer Genomics Proteomics 7(4): 191-205, 2010. PMID: 20656985.

25 Arnett TR: Acidosis, hypoxia and bone. Arch Biochem Biophys 503(1): 103-109, 2010. PMID: 20655868. DOI: 10.1016/ j.abb.2010.07.021

26 Rajpurohit R, Koch CJ, Tao Z, Teixeira CM and Shapiro IM: Adaptation of chondrocytes to low oxygen tension: Relationship between hypoxia and cellular metabolism. J Cell Physiol 168(2): 424-432, 1996. PMID: 8707878. DOI: 10.1002/(SICI)10974652(199608)168:2<424::AID-JCP21>3 .0.CO;2-1

27 Pfander D and Gelse K: Hypoxia and osteoarthritis: How chondrocytes survive hypoxic environments. Curr Opin Rheumatol 19(5): 457-462, 2007. PMID: 17762611. DOI: 10.1097/BOR.0b013e3282ba5693

28 Bartels EM, Fairbank JC, Winlove CP and Urban JP: Oxygen and lactate concentrations measured in vivo in the intervertebral discs of patients with scoliosis and back pain. Spine (Phila Pa 1976) 23(1): 1-7; discussion 8, 1998. PMID: 9460145. DOI: 10.1097/00007632-199801010-00001

29 Urban JP, Smith S and Fairbank JC: Nutrition of the intervertebral disc. Spine (Phila Pa 1976) 29(23): 2700-2709, 2004. PMID: 15564919. DOI: 10.1097/01.brs.0000146499.97948.52

30 Swindle MM, Makin A, Herron AJ, Clubb FJ, Jr. and Frazier KS: Swine as models in biomedical research and toxicology testing. Vet Pathol 49(2): 344-356, 2012. PMID: 21441112. DOI: $10.1177 / 0300985811402846$

31 Luthje FL, Skovgaard K, Jensen HE and Kruse Jensen L: Pigs are useful for the molecular study of bone inflammation and regeneration in humans. Lab Anim 52(6): 630-640, 2018. PMID: 29653496. DOI: $10.1177 / 0023677218766391$

32 Jensen HE, Nielsen OL, Agerholm JS, Iburg T, Johansen LK, Johannesson E, Moller M, Jahn L, Munk L, Aalbaek B and Leifsson PS: A non-traumatic Staphylococcus aureus osteomyelitis model in pigs. In Vivo 24(3): 257-264, 2010. PMID: 20554996.

33 Jensen LK, Jensen HE, Koch J, Bjarnsholt T, Eickhardt S and Shirtliff M: Specific antibodies to staphylococcus aureus biofilm are present in serum from pigs with osteomyelitis. In Vivo 29(5): 555-560, 2015. PMID: 26359414.

Received December 17, 2019

Revised January 7, 2020

Accepted January 8, 2020 